\title{
Niacin Regulates Glucose Reactive Protein (GRP78), Protein Carbonyl Content (PCC) and Malondialdehyde (MDA) in the Hyperglycemic Human Lens Epithelial Cells
}

\author{
Nina Handayani ${ }^{1,2,{ }^{*}}$, Hidayat Sujuti ${ }^{3}$, Nur Permatasari ${ }^{4}$, Achmad Rudijanto ${ }^{5}$
}

\section{Nina Handayani ${ }^{1,2, *}, \mathrm{Hi}-$ dayat Sujuti ${ }^{3}$, Nur Perma- tasari ${ }^{4}$, Achmad Rudijanto $^{5}$}

'Doctoral Program of Medical Science, Faculty of Medicine, Brawijaya University, Malang, East Java, INDONESIA. ${ }^{2}$ Department of Ophthalmology, Faculty of Medicine, Brawijaya University, Saiful Anwar Hospital, Malang, East Java, INDONESIA.

${ }^{3}$ Department of Biochemistry and Molecular Biology, Faculty of Medicine, Brawijaya University, Malang, East Java, INDONESIA.

${ }^{4}$ Department of Pharmacology, Faculty of Medicine, Brawijaya University, Malang, East Java, INDONESIA.

${ }^{5}$ Division of Endocrinology and Metabolic Disease, Department of Internal Medicine, Faculty of Medicine, Brawijaya University, Saiful Anwar Hospital Malang, Malang, East Java, INDONESIA.

\section{Correspondence}

Dr. Nina Handayani

Department of Ophthalmology, Faculty of Medicine, Brawijaya University, Saiful Anwar Hospital, Malang 65245 East Java, INDONESIA.

Phone no : +62818381416

E-mail: handayaninina22@gmail.com; ninahdyn@gmail.com

History

- Submission Date: 12-09-2018;

- Review completed: 02-10-2018;

- Accepted Date: 15-11-2018

DOI : 10.5530/pj.2019.1.2

Article Available online

http://www.phcogj.com/v11/i1

\section{Copyright}

(c) 2019 Phcog.Net. This is an openaccess article distributed under the terms of the Creative Commons Attribution 4.0 International license.

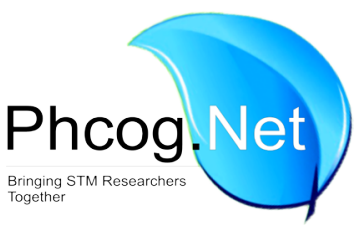

\begin{abstract}
Introduction: Niacin is part of the chemical structure of coenzymes nicotinamide adenine nucleotide (NAD) and nicotinamide adenine dinucleotide phosphate (NADP). Previous studies suggested that a high niacin intake could decrease the prevalence of cataracts, which may delay the onset of diabetic cataract. Aim: The aim of this study was to evaluate the effect of niacin on the hyperglycemia-induced osmotic stress and oxidative stress in human lens epithelial cells. Materials and Methods: Human lens epithelial cells were cultured in a high glucose condition. Oxidative stress markers, including malondialdehyde (MDA), protein carbonyl content (PCC) and glucose reactive protein (GRP), were measured using TBARS analysis (MDA) and ELISA (PCC and GRP) after $72 \mathrm{~h}$ incubation. Results: The MDA levels increased after high glucose administration relative to that in the control group $(p<0.05)$. Further, the groups that were co-treated with niacin showed decrease in the MDA levels for all doses of niacin and the lowest mean MDA level was obtained with $100 \mu \mathrm{M}$ niacin. There was a decrease in the PCC levels for all doses, whereas the lowest mean PCC level was observed at a $100 \mu \mathrm{M}$ niacin dose. The GRP levels increased after high glucose administration as compared with the control group. Also, the groups that were co-treated with niacin exhibited statistically significant reduction. Conclusion: These results suggest that niacin can inhibit the osmotic stress and oxidative stress which may lead to the progression of a diabetic cataract. Also, it may maintain lens transparency by acting as a precursor for glutathione biosynthesis and an antioxidant.

Key words: Diabetic cataract, Glucose, GRP78, MDA, Niacin, Oxidative stress, PCC.
\end{abstract}

\section{INTRODUCTION}

In diabetic patients, cataracts can develop ten years earlier than in patients without diabetes. ${ }^{1}$ The pathogenesis pathways that contribute to the cataractogenesis in diabetic conditions are the polyol pathway (also called as aldose reductase or sorbitol pathway), nonenzymatic glycation pathway, oxidative stress pathways, unfolded protein response (UPR) and apoptotic pathways. The polyol pathway activates oxidative stress and hyperglycemia increases the occurrence of protein glycosylation and free radical formation. Importantly, oxidative stress can trigger the UPR which can lead to decrease of lens antioxidants such as glutathione thereby increasing the formation of Reactive Oxygen Species (ROS). ${ }^{1,2}$

The Blue Mountain Study suggested that there is a relationship between cataracts and nutrients including macronutrients, micronutrients and antioxidant vitamins. The study with 2900 populations in Australia within a 49-97 years age range showed that a high niacin intake could decrease the prevalence of cataracts with odds ratio 0.6 (95\% CI, 0.4-0.9). ${ }^{2}$ Niacin, also known as nicotinic acid is part of the chemical structure of coenzymes nicotinamide adenine nucleotide (NAD) and nicotinamide adenine dinucleotide phosphate (NADP). Enzymes that require NAD/NADP are involved in various processes such as oxidation and reduction reactions in energy production, cholesterol metabolism, fatty acid oxidation, glucose degradation, the pentose phosphate pathway, amino acid synthesis and degradation, resistance to pathogenic bacteria, GSH regeneration from GSSG and synthesis of glucocorticoids and sex hormones. ${ }^{3}$

We hypothesized that niacin can delay the onset of diabetic cataract. Therefore, in the present study, we examined the possible protective effect of nicotinamide against oxidative damage, in terms of lipid peroxidation (MDA level measurement), protein oxidation (protein carbonyl content measurement) and endoplasmic reticulum stress (glucose reactive protein/GRP measurement) in the high glucose treated human lens epithelial cell culture. The results demonstrated that nicotinamide can protect against
Cite this article: Handayani N, Rudijanto A, Sujuti H, Permatasari N. Niacin Regulates Glucose Reactive Protein (GRP78), Protein Carbonyl Content (PCC) and Malondialdehyde (MDA) in the Hyperglycemic Human Lens Epithelial Cells. Pharmacog J. 2019;11(1):08-11. 
damage in proteins, lipids and oxidative stress in the endoplasmic reticulum (ER). The inhibitory effect seems to be more pronounced against oxidative stress in the ER.

\section{MATERIALS AND METHODS}

\section{Cell culture and treatments}

Human lens epithelial (HLE-B3) cell line was purchased from ATCC (Manassas, VA) and stock cultures were maintained in EMEM medium (Gibco) supplemented with $20 \% \mathrm{FBS}$, penicillin $(50 \mathrm{U} / \mathrm{mL})$ and streptomycin $(50 \mathrm{U} / \mathrm{mL})$ at $37^{\circ} \mathrm{C}$ in the presence of $5 \% \mathrm{CO}_{2} .5 \times 10^{4}$ cells were seeded into 24 well plates for overnight in EMEM medium containing $10 \% \mathrm{FBS}$ and treated with $25 \mathrm{mM}$ glucose and co-treated with five different doses of niasin $(12.5,25,50,100,200 \mu \mathrm{M})$ and harvested after $72 \mathrm{~h}$.

\section{MDA analysis}

After $72 \mathrm{~h}$ with exposure to high glucose $(25 \mathrm{mM})$ and co treated with five different doses of niacin $(12.5,25,50,100,200 \mu \mathrm{M})$, cells were harvested and lysed and then centrifuged at $10000 \mathrm{rpm}$ for $2-3 \mathrm{~min}$. The protein were isolated from culture cell and protein concentrations were measured using the nanodrop protein methods and followed MDA determination (TBARS methods) using commercial assay kits according to the manufacturer's instruction (Life Science Specialties, LCC). The absorbance was measured at $532 \mathrm{~nm}$ using spectrophotometer.

\section{ELISA Protein Carbonyl Content (PCC) and Glucose Reac- tive Protein (GRP 78) analysis}

In separate experiment, cells were harvested, and the cell lysate was collected for ELISA Protein Carbonyl Content (PCC) Analysis (MyBioSource) and ELISA Glucose Reactive Protein (GRP78/BiP) Analysis (MyBioSource) using commercial assay kits according to the manufacturer's instruction. Protein concentrations were measured using the nano drop protein methods and followed PCC and GRP determination (ELISA). The absorbance was measured at $532 \mathrm{~nm}$ using spectrophotometer.72 $\mathrm{h}$.

\section{Statistical analysis}

One-way ANOVA or Kruskal Wallis was used for testing statistical significance between groups. The data normality was tested with Saphiro Wilk and Levene's test was used for testing homogenity of the data between groups. $p<0.05$ was considered significant.All data were dealt by SPSS 18.0 statistical package.

\section{RESULTS}

Based on Figure 1, It can be seen that the highest average MDA rate is in the $\mathrm{K}+$ group $(1.58 \pm 1.112)$ and the lowest average MDA rate is in the group treated with high glucose and niacin $100 \mu \mathrm{m}(0.05 \pm 0.039)$. Based on the average, there is a difference of mean MDA rate between each group. This study proved that high glucose was promoted the increasing of MDA level in the lens cells $(\mathrm{K}+$ ). In P1, P3 and P5 treatment of Niacin, the average of MDA level almost similar with a control group and in P2 and $\mathrm{P} 4$ treatment of niacin, the average MDA level lowest than a control group.

Based on Figure 2, It can be seen that the highest average PCC rate is in the $\mathrm{K}+$ group $(1.23 \pm 0.265)$ and the lowest average PCC rate is in the group treated with high glucose and niacin $100 \mu \mathrm{m}(0.730 \pm 0.054)$. This study proved that high glucose was promoted the increasing of PCC level in the lens cells $(\mathrm{K}+)$. In P1, P2, P3 of Niacin, the average of PCC level almost reach the average of a control group and in $\mathrm{P} 4$ treatment of niacin $(100 \mu \mathrm{m})$, the average PCC level lowest than a control group

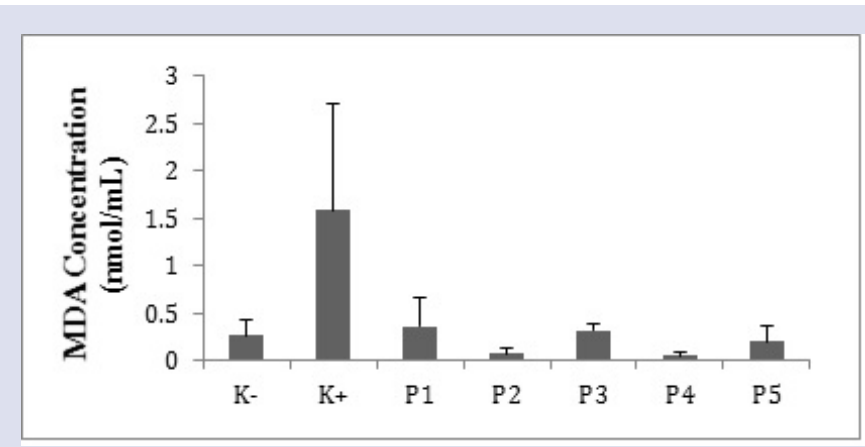

Figure 1: Administration of niacin were decreased the stress oxidative level (MDA) that produce by human lens epithelial cells in high glucose level. Data were analyzed using MDA TBars-methods and tabulated into Microsoft excel. Data are mean \pm SD values of each group with three replication. K-: control group (no glucose no treatment), K+ : Lens epithel cells culture with high glucose $(25 \mathrm{mM}) ; \mathrm{P} 1$ : Lens epithel cells culture with high glucose cotreated with niasin $12.5 \mu \mathrm{M}$; P2 : Lens epithel cells culture with high glucose cotreated with niasin $25 \mu \mathrm{M}$; P3 : Lens epithel cells culture with high glucose cotreated with niasin $50 \mu \mathrm{M}$; P4: Lens epithel cells culture with high glucose cotreated with niasin $100 \mu \mathrm{M}$; P5 : Lens epithel cells culture with high glucose cotreated with niasin $200 \mu \mathrm{M}$

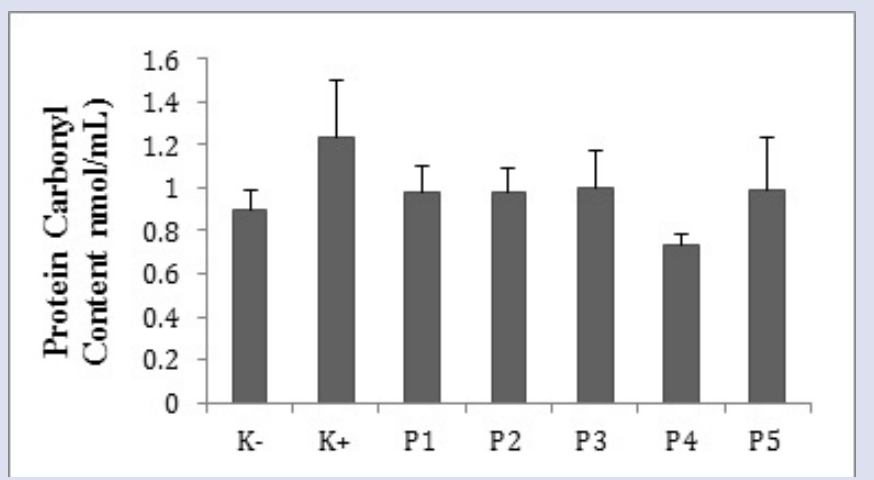

Figure 2: Administration of niacin were decreased the stress oxidative level in the protein carbonyl content (PCC) that produce by human lens epithelial cells in high glucose level. Data were analyzed using Human ELISA PCC and tabulated into Microsoft excel. Data are mean \pm SD values of each group with three replication. K: control group (no glucose no treatment), $\mathrm{K}+$ : Lens epithel cells culture with high glucose; P1: Lens epithel cells culture with high glucose cotreated with niasin $12.5 \mu \mathrm{M} ; \mathrm{P} 2$ : Lens epithel cells culture with high glucose cotreated with niasin $25 \mu \mathrm{M}$; P3: Lens epithel cells culture with high glucose cotreated with niasin 50 $\mu \mathrm{M}$; P4: Lens epithel cells culture with high glucose cotreated with niasin $100 \mu \mathrm{M}$; P5: Lens epithel cells culture with high glucose cotreated with niasin $200 \mu \mathrm{M}$.

This next step was to evaluate the endoplasmic reticulum stress marker (GRP78/BiP) induced by high glucose. We observed that the average of GRP level in Figure 3 increase after exposed with high glucose $(\mathrm{K}+)$ comparing with the control group (K-) $(0.202 \pm 0.02$ vs $0.129 \pm 0.02)$. In P1 treatment of niacin $(50 \mu \mathrm{m})$, the average of GRP level almost reach the average of a control group.

\section{DISCUSSION}

Lens epithelial cells maintain the normal metabolism and keep the lens clear. The oxidative stress reaction that is induced by high glucose can 


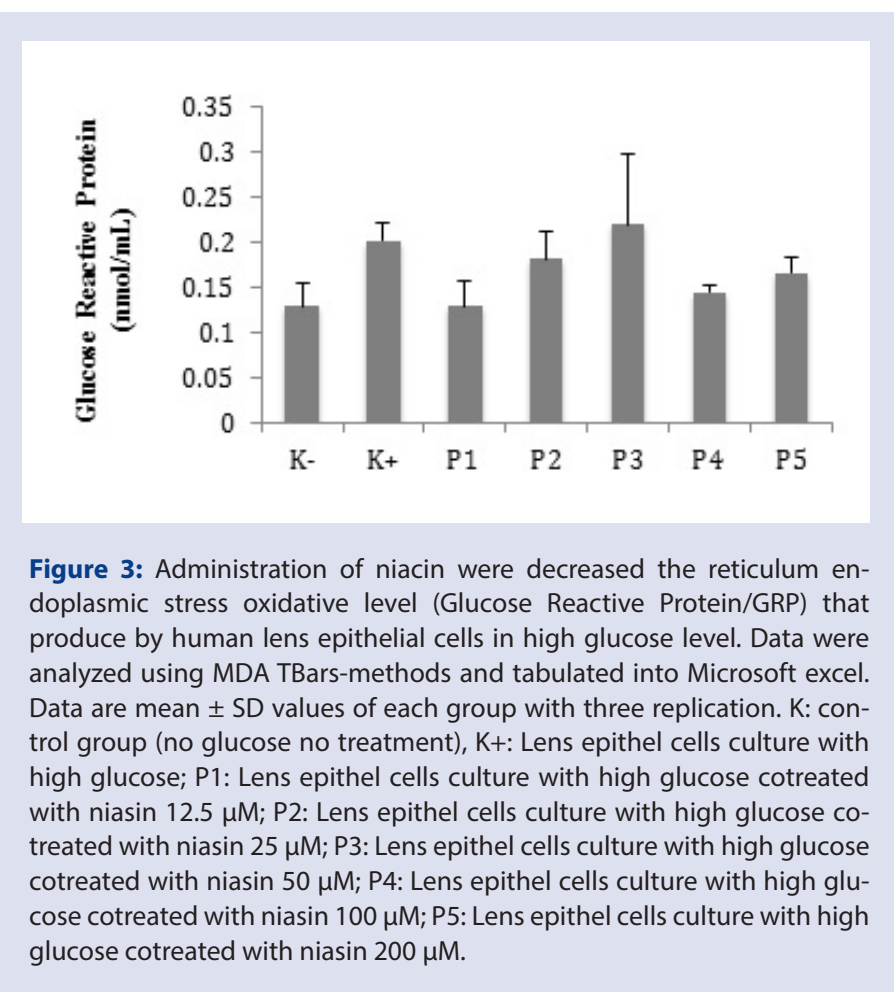

increase ROS and development of the cataract. In this study, we found that high concentration of glucose can induce oxidative stress in the endoplasmic reticulum, increase lipid peroxidation and protein oxidation in the human lens epithelial cells.

The data in Figure 1 show that the MDA levels increased after high glucose administration relative to those in the control group $(p<0.05)$. Further, the groups that were co-treated with niacin showed decrease in the MDA levels for all doses of niacin and the lowest mean MDA level was obtained for the $100 \mu \mathrm{M}$ niacin dose. Moreover, the data in Figure 2 show an increase in the protein oxidation level after high glucose administration as compared with the control group and a decrease in the PCC levels in the groups that were co-treated with niacin with the lowest mean PCC level at a dose of $100 \mu \mathrm{M}$ niacin. Although these data do not show any significant differences between groups, the decrease of the PCC level can be clearly seen in the Figure 2 .

The study by Kamat and Devasagayam ${ }^{4}$ demonstrated the effect of nicotinamide in the rat brain mitochondria by showing that nicotinamide significantly inhibited both lipid peroxidation and protein oxidation in the ascorbate- $\mathrm{Fe}^{2+}$ system in the rat brain mitochondria. Clearly, these results are consistent with our results.

Niacin cannot be directly transformed into nicotinamide, but it acts as a precursor for NAD and NADP coenzyme in vivo. ${ }^{5} \mathrm{NAD}$ is transformed into NADP through a phosphorylation process in the presence of NAD+ kinase enzyme. Notably, NADP and NAD function as coenzymes for various dehydrogenation reactions and are also involved in some hydrogen transfer processes. While NAD is very important in terms of the catabolism of fats, carbohydrates, proteins, alcohol and also for cell signaling and DNA repair; NADP, on contrary, is important in anabolic reactions such as fatty acids and cholesterol synthesis. ${ }^{6}$ Niacin, a precursor for NAD and NADP, is also involved in DNA repair processes. ${ }^{3,7} \mathrm{NAD}+$ and $\mathrm{NADP}+$ play a key role as electron carriers in energy transfer. NADH is a reduced form of $\mathrm{NAD}+$, while NADPH is a reduced form of NADP+.
Many enzymes require the niacin derived coenzymes NAD and NADP. In $\mathrm{NAD}+$ synthesis, nicotinamide joins with ribose and $\mathrm{ADP}$ to form NAD+. The addition of two phosphate groups to the two positions of the adenyl nucleotide in NAD+ via an ester linkage forms NADP+. Also, NAD (and niacin) can also be synthesized in the liver from the amino acid tryptophan. ${ }^{8,9}$ Moreover, NADPH serves as a reducing agent to regenerate antioxidant systems such as thioredoxins and glutathione. In turn, to maintain cellular NADP in a reduced state, dedicated systems such as glucose-6-phosphate dehydrogenase in the cytosol and isocitrate dehydrogenase 2 in the mitochondria are upregulated upon oxidative assaults. ${ }^{10}$

In the diabetic condition, the concentration of glucose in lens cell is too high. Hence, glucose is converted into sorbitol, with the help of the enzyme aldose reductase, followed by its oxidization to fructose. Further, activation of polyol pathways causes increased glucose metabolism to sorbitol with the help of the aldose reductase enzyme and consumes the NADPH cofactor. The role of NADPH as a cofactor for the conversion of glucose to sorbitol may compete with its function in the conversion of oxidized glutathione (GSSG) to reduced glutathione (GSH). Therefore, the addition of niacin in this study was expected to maintain the synthesis of NADP and NADPH through the pentose-phosphate pathway so that the NADPH cofactors necessary for GSH regeneration remain available in sufficient quantities.

In the next experiment, we measured the Glucose Reactive Protein (GRP) level. Glucose Reactive Protein is a marker of endoplasmic reticulum stress. The data in Figure 3 show that the GRP levels increased after high glucose administration as compared with the control group. Further, in the groups that were co-treated with niacin, GRP levels significantly decreased for $12.5 \mu \mathrm{M}$ and $100 \mu \mathrm{M}$ niacin doses $(p<0.05)$ as compared with the group that was treated only with high glucose.

The endoplasmic reticulum (ER) stress can activate the UPR and the UPR activation pathway of the lens can mediate UPR specific translation activation. The production of ATF6 $(\mathrm{N})$ and XBP1 can alter the fibrous cell transcription program by upregulatinggenes involved in the folding process in ER Then, the biogenesis of ERin the lens fiber cells can cause degradation of the nucleus and cytoplasmic organelles. ${ }^{11-13}$ PKR-like ER kinase (PERK) which mediates translation, can regulate lens cell differentiation by decreasing the synthesis of crystalline and specific fiber cell proteins that are required for cell differentiation.

The UPR is closely related to the presence of osmotic and oxidative stress in the lens. Mulhern et al. conducted a series of studies to reveal this relation. In epithelial cultures of lenses on a Minimal Essential Medium (MEM) and mannitol, the Aldose Reductase Inhibitor (ARI) levels (as the osmotic stress marker) and GRP78/BiP levels (as the UPR marker) increased. This suggests that the induction of UPR and aldose reductase (AR) is the result of extracellular osmotic stress in the lens epithelial culture. Furthermore, UPR can be induced by oxidative stress, as demonstrated by exposure of epithelial lens cells to $\mathrm{H}_{2} \mathrm{O}_{2}$, leading to increased cell death and GRP78/BiP levels in a time- and concentration-dependent manner. ${ }^{14}$

\section{CONCLUSION}

Niacin is useful as precursor of NAD and NADP and a natural antioxidant. It can protect the lens from cataractogenesis that may occur due to increased generation of ROS in the lens epithelial cells under hyperglycemic conditions.

\section{ACKNOWLEDGEMENT}

The researcher delivers the gratitude for the grant support provided by Indonesia Ministry of Technology, Research and Education. 


\section{CONFLICT OF INTEREST}

The authors declare no conflict of interest.

\section{ABBREVIATIONS}

ELISA: Enzyme-linked immunosorbent assay; GRP78: Glucose Reactive Protein; MDA: Malondialdehyde; NAD: Nicotinamide Adenine Nucleotide; NADP: Nicotinamide Adenine Dinucleotide Phosphate; PCC: Protein Carbonyl Content; ROS: Reactive Oxygen Species.

\section{REFERENCES}

1. Pokupec R, Kalauz M, Turk N, Turk Z. Advanced glycation end products in human diabetic and non-diabetic cataractous lenses. Graefe's Arch Clin Exp Ophtalmol. 2003;241(5):378-84

2. Cumming RG, Mitchell $P$, Smith W. Diet and Cataract: the Blue Mountains Eye Study. Ophthalmology. 2000;107(3):450-6.

3. Kirkland J. Niacin Status Impacts Chromatin Structure. J Nutr. 2009;139(12):2397-401.

4. Kamat JP, Devasagayam TP. Nicotinamide (vitamin B3) as an Effective Antioxidant against Oxidative Damage in Rat Brain Mitochondria. Redox Rep. 1999;4(4):179-84.

5. Benavente CA, Jacobson EL. Niacin Restriction Upregulates NADPH oxidase and ROS in human keratinocytes. Free Radic Biol Med. 2008;44(4):527-37.

6. Wan P, Moat S, Anstey A. Pellagra: a Review with emphasis on photosensitivity. Br J Dermatol. 2011;164(6):1188-200.

7. Kennedy DO. B vitamins and the Brain: Mechanisms, Dose and Efficacy-A Review. Nutrients. 2016;8(2):68

8. Cox M, Lehninger AL, Nelsom DR. Lehninger principles of biochemistry New York: Worth publishers. 2000

9. Higdon J [homepage on the Internet]. Niacin. Linus Pauling Institute (Oregon State University [updated 2002 May 16; cited 2007 January 28]. Available from: http://lpi.oregonstate.edu/mic/vitamins/niacin.

10. Agledal L, Niere M, Ziegler M. The phosphate makes a difference: cellular func tions of NADP. Redox Rep. 2010;15(1):2-10

11. Sriburi R, Jackowski S, Mori K, Brewer JW. XBP1: a link between the unfolded protein response, lipid biosynthesis and biogenesis of the endoplasmic reticulum. J Cell Biol. 2004;1679(1):35-41.

12. Sriburi R, Bommiasamy H, Buldak GL, Robbins GR, Frank M, Jackowski S, et al. Coordinate regulation of phospholipid biosynthesis and secretory pathway gene expression in XBP-1(S)-induced endoplasmic reticulum biogenesis. J Biol Chem. 2007;282(10):7024-34

13. Bommiasamy $H$, Back SH. ATF6 alpha induces XBP1-independent expansion of the endoplasmic reticulum. J Cell Sci. 2009;122(Pt 10):1626-36.

14. Mulhern ML, Madson CJ, Danford A, Ikesugi K, Kador PF, Shinohara T. The unfolded protein respons in lens epithelial cells from galactosemic rat lenses. Invest Ophthalmol Vis Sci. 2006;47(9):3951-9.

\section{GRAPHICAL ABSTRACT}

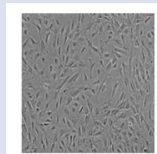

Human lens epithelial cells
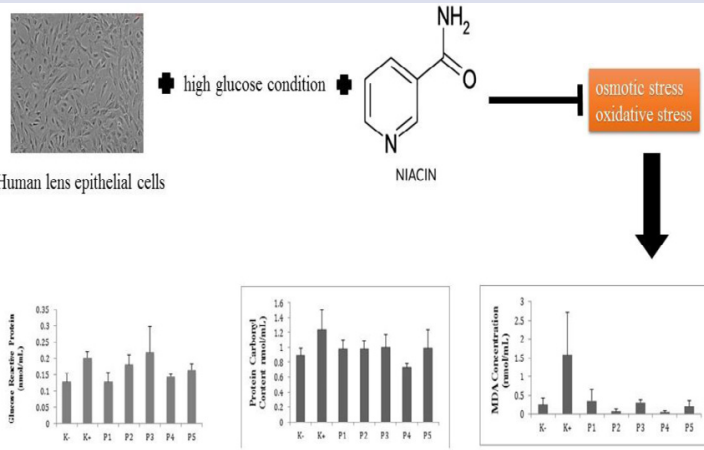

malondialdehyde (MDA)
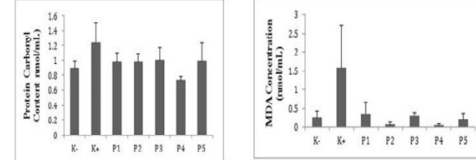

protein carbonyl content (PCC) $\downarrow$

glucose reaclive protein (GRP)

\section{SUMMARY}

- The effect of niacin were evaluated on the hyperglycemia-induced osmotic stress and oxidative stress in human lens epithelial cells. The level of MDA, PCC and GRP were measured using TBARS analysis (MDA) and ELISA (PCC and GRP). The MDA levels increased significantly after high glucose administration in the control group $(p<0.05)$. There was a decrease in the PCC levels for all doses, whereas the lowest mean PCC level was observed at a $100 \mu \mathrm{M}$ niacin dose. The GRP levels increased after high glucose administration as compared with the control group. Also, the groups that were co-treated with niacin exhibited statistically significant reduction. Our findings suggest that niacin can inhibit the osmotic stress and oxidative stress which may lead to the progression of a diabetic cataract. It may maintain lens transparency by acting as a precursor for glutathione biosynthesis and an antioxidant.

\section{ABOUT AUTHORS}

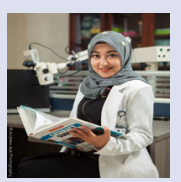

Dr. Nina Handayani, Sp.M (K) received her eye specialist degree in Ophthalmology, Department at Faculty of Medicine, Brawijaya University. She is a Lecturer at Faculty of Medicine, Brawijaya University. She is currently a doctoral student at Faculty of Medicine Brawijaya University. Her research interest include Opthalmology related with Niacin and Glutathione.

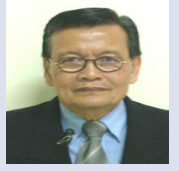

Prof. Dr. Achmad Rudijanto, Sp.P. KE is a professor at Department of Internal Medicine, Brawijaya University. He has expertise in calcium ion in diabetes mellitus, Cardiovascular and neuroscience.

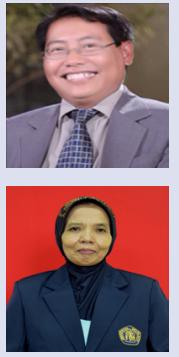

Dr. Hidayat Sujuti, PhD is a Lecturer at Biochemistry and Biomolecular Department, Brawijaya University. His research interest includes Biochemistry \& Biomolecular and Ophthalmology.

Dr. Nur Permatasari, M.Si: is a lecturer at Faculty of Medicine, Brawijaya University. Her research interest includes herbal medicine.

Cite this article: Handayani N, Rudijanto A, Sujuti H, Permatasari N. Niacin Regulates Glucose Reactive Protein (GRP78), Protein Carbonyl Content (PCC) and Malondialdehyde (MDA) in the Hyperglycemic Human Lens Epithelial Cells. Pharmacog J. 2019;11(1):08-11. 